\title{
Regret, Resilience, and the Nature of Grief
}

\author{
Michael Cholbi \\ Professor of Philosophy, California State Polytechnic University, U.s. \\ mjcholbi@cpp.edu \\ PROOF VERSION - PLEASE CITE FULL PUBLICATION TEXT \\ AVAILABLE AT https://brill.com/view/journals/jmp/jmp-overview.xml
}

Vain creatures that we are, most of us hope to be grieved after our deaths. To learn that our loved ones will not grieve for us or that their anguish will subside quickly might imply something unsettling about ourselves: that we really do not matter as much to others as we ordinarily suppose.

Empirical studies of grief indicate that these egoistic hopes often go unrealized, however. Far from being permanent, the pains of grief, while often initially intense, tend to dissipate in a few months, rather than years. In the immediate aftermath of a spouse or loved one's death, grief is nearly always detrimental to subjective well-being. Yet most individuals return to their antecedent level of well-being surprisingly quickly. Our apparent ability to move on, or move beyond grief, seems to indicate that our "emotional immune system" deals with the pain of loss with far more resilience than we might expect. ${ }^{1}$

In a well-regarded article, Dan Moller has argued that these empirical findings do not show that we fail to care (or care very little) about our loved ones while they are alive. However, such findings give us reason to regret our apparent resilience in the face of grief, according to Moller. ${ }^{2}$ Because our emotions enable us to "perceive value," our apparent ability to adapt to the loss of our loved ones suggests that we eventually end up blind to the value of our loved ones and our relationships with them, he argues. We should thus regret this resilience on epistemic grounds, inasmuch as it precludes emotional engagement with our lost loved ones and "so deprives us of insight into our own condition."

1 George Bonnano summarizes the empirical findings regarding grief and 'recovery' in Chapter 4 of The Other Side of Sadness: What the New Science of Bereavement Tells Us about Life After Loss (Basic Books, 2009).

2 "Love and death," Journal of Philosophy 104 (2007): 301-316. For other discussions of this article, see Aaron Smuts, "Love and death: The problem of resilience," in M. Cholbi (ed.), Immortality and the Philosophy of Death (Rowman and Littlefield, 2015), pp. 173-188, and Ryan Preston-Roedder and Erica Preston-Roedder, "Grief and recovery," in A. Gotlib, ed. The Moral Psychology of Sadness (London: Rowman \& Littlefield International, forthcoming).

3 "Love and death," p. 311. 
Moller's conclusion is, I shall argue, correct in broad outline. Yet he reaches this conclusion without reference to any larger theoretical framework concerning grief's nature or its normative significance to our lives. My goals in this article are to provide such a framework and to thereby offer a theoretically richer vindication of Moller's conclusion. I intend this framework to be largely neutral, however, among philosophical theories of the emotions. The conclusions I reach regarding the nature and significance of grief are ones that should be acceptable to those who hold that emotions are feelings or awarenesses of bodily states, judgments, or cognitions of value, etc. Nevertheless, Moller's suggestion that grief is an emotional perception will serve as a useful platform by which to defend three claims that, I shall demonstrate, are central to the nature of grief. First, grief is not a single 'perceptual' affective state but an emotional process; second, grief registers the value of deceased loved ones by attending to that value over time rather than perceiving that value all at once; and third, grief is not a passive state of emotional receptivity but an activity driven by the goal of placing the bereaved's relationship with the deceased on new terms. Having defended these three claims regarding grief's nature, I then turn to the question of whether the characteristic resilience we show in the face of grief merits regret. I argue that, because the suffering or anguish we associate with grief is only one element of our normatively significant emotional engagement with a deceased person, the cessation of this suffering or anguish does not exhaust the considerations relevant to determining whether this cessation merits regret. More specifically, the onset (and abatement) of this suffering must instead be evaluated with respect to its role in achieving a good for which grief represents an especially fruitful opportunity, namely self-knowledge or self-understanding. And because grief is an activity rather than a perception, the regret at issue turns out to be species of what Bernard Williams called agent-regret, rather than spectator-regret. We can, therefore, fail ourselves by failing to grieve well.

\section{Grief as a Process of Emotional Attention}

On one level, empirical findings indicating our resilience in the face of grief may be encouraging. We grieve less than we might predict, and insofar as grief is an unpleasant experience, that we so readily adapt to such losses may be good for us overall. Nevertheless, that our grief is more short lived or moderate than we anticipate may seem to be grounds for distress or regret. Moller proposes that such resilience may justify distress or regret because our emotions 
enable us to track or register what is valuable to us. That we are unexpectedly resilient in the face of loss - that the suffering of grief fades more fully and more quickly than we would predict-thus implies that we become epistemically severed from our deceased loved ones. "Our response over time" to the loss of a loved one "does not seem to reflect the preciousness" that loved one has to us, according to Moller. We are thereby immediately deprived of an appreciation of their significance to us and ultimately deprived of "insight into our own condition."

I broadly agree with Moller's premise that emotional states track value and with his conclusion that "insight into our own condition" is normatively at stake in grief. But his general line of argument benefits from being situated in a more detailed theoretical account of grief's nature and significance than Moller advances.

Grief registers a state of affairs that is evaluatively significant to the bereaved. We shall have occasion later to say more precisely what that state of affairs is, but for now, less us simply say that grief registers a loss of some kind. But how does grief register a loss to the bereaved? While the vast majority of philosophers agree that emotions in some manner register evaluatively significant states of affairs, they differ as to what is essential in explaining this relation. I do not aim to settle such disputes here. Rather, I use as my launching point Moller's suggestion that because emotions are "part of the means by which we perceive value," ${ }^{\prime 4}$ grief registers loss via a perception of that loss. I do so largely for expository convenience rather than from any bias in favor of a 'perceptual' theory of emotions.

It is difficult to know how to interpret the claim that emotions are 'perceptions' of evaluatively significant states of affairs. Are we to take this claim literally, so that just as visual phenomena are perceptions of observable properties such as size or shape, emotions are perceptions of normative properties such as (say) dangerousness or lovability? Or is the perceptual language here more metaphorical? For our purposes, the metaphysical specifics of emotional perception can be set aside so as to focus on the epistemic connotations of the thesis that emotions are perceptions of value. If emotions are perceptions of value, then to be in a particular emotional state provides reasons related to the facts the state 'perceives.' To hear the sizzle of water is to be in a state that gives the hearer an immediate or non-inferential reason to believe that the kettle on the stove has overflowed. Similarly, to feel (say) fear is to be in a state that gives the experiencer an immediate or non-inferential reason to believe that something in her environment is threatening to her or to what she cares about.

4 “Love and death," p. 311, emphasis added. 
In both cases, facts in the world casually elicit 'perceptions' in individuals that generate accurate but defeasible attitudes about those facts.

Applied to grief, this model implies that grief is a perception of loss, a feeling directed at, and elicited by awareness of, that loss. In feeling grief, a person acquires a reason (or additional reason) to form further beliefs or attitudes related to that loss.

No doubt grief involves perceptions of loss. But this model underdescribes the emotional complexity of grief. While we sometimes use 'grief' to denote only the sadness associated with grieving, grief does not seem like $a$ perception, a single sensation-like state directed at the world. Rather, grief involves a concatenation of emotional states or perceptions. Thanks largely to the work of Elizabeth Kubler-Ross and John Bowlby, grief is now recognized as a process with delineable stages. ${ }^{5}$ Grief qua process will include moments of suffering. Yet it will also include other emotional states. What has come to be seen as the Kubler-Ross 'theory' - that those who grieve proceed through a five-stage process of denial, anger, bargaining, depression, and acceptance-is incorrect. Very few instances of grief conform to this process. ${ }^{6}$ Nevertheless, as many philosophers have concluded, grief cannot be straightforwardly modeled on emotions like fear or anger because grief is not a single mental event or episode. Rather, the process of grief involves a series of emotional conditions or events. As Wittgenstein remarked, ${ }^{7}$ while it is coherent to utter "For a moment I felt intense pain," to utter "For a moment I felt intense grief" is discursively amiss precisely because it reports one's grief as if it were a momentary sensation. Suffering is no doubt an essential constituent of grief. But it should not be identified with grief.

Thus, if grief is perception-like in giving us reasons to form attitudes about the loss that elicits it, then because grief nearly always involves multiple 'perceptions' of different emotional kinds, grief seems to give us reasons to form many attitudes about that loss. A grief episode containing (say) sadness, anger, and anxiety gives us reason to form several attitudes concerning its object. Grief is therefore not as epistemically well-behaved as most other

5 On Death and Dying (New York: Scribner, 1997), Loss: Sadness and Depression (New York: Basic Books, 1982).

6 See Paul K. Maciejewski, Baohui Zhang, Susan D. Block, and Holly G. Prigerson, "An empirical examination of the stage theory of grief," Journal of the American Medical Association 297 (2007): 716-723 (popularly known as the "Yale bereavement study"), and Ruth Davis Konigsberg, The Truth about Grief: The Myth of Its Five Stages and the New Science of Loss (New York: Simon and Schuster, 2011).

7 Philosophical Investigations (Oxford: Blackwell, 1958), pp. 174-75. 
emotions; rather than instantiating a one-to-one relation, wherein a given fact $\mathrm{F}$ elicits perception $\mathrm{P}$, grief's characteristic pattern is that a given fact $\mathrm{F}$ (or a complex set of facts F) elicits multiple emotional perceptions. This affective many-sidededness of grief further suggests that its object is more normatively complex than other emotions. (More on this to come.)

There is a second sense in which describing grief as a perception may mislead. Our emotional perceptions can depend on background beliefs and dispositions, some of which are irrational. Phobias, for instance, lead us to fear what does not merit fear. But standardly, when emotions provide us evidence concerning the normative significance of various facts, they do so in a relatively decisive way. That the thunder clap causes fear is compelling evidence of the storm's dangerousness; that the insult causes anger is compelling evidence of its utterer being unkind; etc. And often, emotions dissipate as their objects dissipate. Our fear abates as the storm ends, our anger softens once the utterer apologizes, etc.

Grief, in contrast, does not so much settle the question of the normative significance of its object as it does invite further engagement with it. Despite the painfulness of grief, we are often drawn to grieve, finding even grief's sufferings inexplicably attractive. St. Augustine described the grief he felt upon the death of a childhood friend thusly:

My heart was black with grief. Whatever I looked upon had the air of death. My native place was a prison-house and my home a strange unhappiness. The things we had done together became sheer torment without him. My eyes were restless looking for him, but he was not there. I hated all places because he was not in them.... I had no delight but in tears, for tears had taken the place my friend had held in the love of my heart. ${ }^{8}$

Augustine searches plaintively for his friend but finds 'delight' in that tearful search. Unlike other emotions, his grief did not provide him a part representation of the normative significance of his friend's death. His grief instead motivates further interrogation of, or engagement with, an object that Augustine cognizes only dimly.

Augustine's account of his own grief underscores how the process of grief functions evaluatively more as a form of temporally extended attention to some fact rather than a complete and decisive perception of that fact. Michael

8 Confessions, F. Sheed, trans., and M.P. Foley, ed. (Indianapolis: Hackett, 2006) [original composition AD 397-40o], pp. 59-6o. 
Brady has recently defended an account of the nature of emotion along these lines. On his account, emotional experiences begin with automatic and largely haphazard evaluative appraisals of facts. But such experiences are signals that some fact requires our attention, and unlike standard perceptual experiences, which generally silence justificatory questions about the nature of the facts that are their objects, emotional experiences often raise the question of the nature or significance of the facts that are their objects. Emotional experiences thus motivate us to attend to these facts so as to inquire further into their nature or significance, thereby instigating rather than terminating inquiry into their objects. As Brady describes it, emotions come to "capture and consume" our attention. This sustained attention provides us the opportunity to revise and correct our initial evaluative appraisals so as to align our responses with the objective evaluative properties of the facts that prompted those initial appraisals. Emotions thus relate to value not as authoritative perceptions of evaluative facts but as states that direct us to attend to, and subsequently size up, the evaluative facts that causally elicit them. ${ }^{9}$

As Brady observes, emotions are often immediate but then unfold or change form gradually. Such appears to be the case with grief. The various stages of grief, suffering included, have a common cause. That cause is more evaluatively complex than are the causes of many emotions. More will be said in section 2 about whom and what we grieve for. For the moment though, it suffices to observe that our relationships to those we grieve are often multifaceted. For example, it would be unlikely for a parent's death to have only one kind of evaluative significance for a child or to conform to a simple stimulus-response script. For during our lifetimes, our relationships to our parents undergo many oscillations and transformations. The toddler who rages at her parent one moment coos happily the next. The sullen teenager who resents her parents' heavy-handed discipline later comes to appreciate the positive effects of that discipline and thus admires their steadfastness. The adult child who can enjoy his parents' company as if they are peers must later confront a dying and intensely vulnerable parent. It would be surprising then for children to react to their parents' death with a single, unalloyed emotional response.

Note that because grief adheres to the attentional model of emotion espoused by Brady, the various mental states or conditions that comprise a grief episode are not simply unrelated items temporally bundled together. The components of this bundle are dictated by the normatively significant natural and social facts that surround a grief episode. These facts may include the existing

9 Emotional Insight: The Epistemic Role of Emotional Experience (Oxford: Oxford University Press, 2013), pp. 87-97. 
emotional dispositions of the bereaved (his emotional 'personality'), the nature of the attachment between the bereaved and the deceased, the bereaved's value commitments, prior grief experiences, the circumstances surrounding the death, and other concurrent stresses. ${ }^{10}$ These facts in turn generate the structured complex of emotional states that constitute an episode of grief. The affective states that occur earlier in the grief process are likely to be the products of reflexive emotional mechanisms, whereas the latter states may be more reflective, as the other's death comes to fully 'sink in.' This is not to suggest that the later emotional stages are necessarily more accurate evaluative appraisals of the facts that prompt grief. The stages of grief need not be teleologically ordered and none of these stages need be epistemically privileged, for they work in concert to depict our relationship with the deceased. But grief often has an emotional cadence, a sequence of emotional arousals and resolutions of its own. ${ }^{11}$ Hence, the order in which the various episodes that constitute grief occur can matter to what grief is like.

Some further hypothesize that grief processes are structured in the form of narratives. ${ }^{12}$ On this picture, the identity conditions for a grief episode include not only the bereaved, the object of her grief, and the emotional states that serve as the components of the grief process, but also the temporal and narrative interrelations among those states. A narrative is a sequenced set of actions and reactions. 'Juliet stabs herself' would be a very different narrative element had it occurred before 'Romeo drinks the poison.' The elements of a narrative constitute the narrative, but the overall narrative assigns the elements their respective roles. To assert that grief episodes are narratives is to claim that an episode with the pattern anger-apathy-sadness-acceptance is a crucially different episode than one containing the same component states but ordered differently in time, say, sadness-anger-apathy-acceptance. These patterns thus

10 J. William Worden, Grief Counselling and Grief Therapy: A Handbook for the Mental Health Practitioner, $4^{\text {th }}$ edition (New York: Springer, 2009), pp. 57-75. Daniel C. Russell, Happiness for Humans (Oxford: Oxford University Press, 2012), pp. 218-25 summarizes many of the main research findings in this area. See also Michael Cholbi, "Grief's rationality, backward and forward," Philosophy and Phenomenological Research 94 (2017): 255-272, doi: 10.1111/ phpr.12353.

11 David Velleman, "Narrative explanation," Philosophical Review 112 (2003): 1-25.

12 Robert Solomon, True to Our Feelings (Oxford: Oxford University Press, 2008), pp. 76-77; Peter Goldie, "Grief: A narrative account," Ratio 24 (2011): 119-137; Kathleen Marie Higgins, "Love and death," in J. Deigh (ed.), On Emotions: Philosophical Essays (Oxford: Oxford University Press, 2013), pp. 159-178; and Line Ryberg Ingerslev, “Ongoing: On grief's openended rehearsal," Continental Philosophy Review, forthcoming [https://link.springer.com/ article/10.1007/s11007-017-9423-7], doi: doi.org/10.1007/s11007-017-9423-7. 
take on a narrative quality in that the temporal order of these emotional states contributes to the evaluative significance of the states themselves.

As we shall see later on, I hold that grief often plays a role in the narratives of our lives overall. Furthermore, inasmuch as grief is a state of ongoing attention to some normatively significant fact(s), it often resembles narratives in being an effort to make sense of normatively significant facts. Grief experiences (and again I have in mind the totality of emotional states that constitute the grief process, not just the suffering) are not given to us as normatively transparent packages with clearly delineated parts and pre-established meanings. Indeed, the evaluative opacity of grief - that its importance and the importance of the loss it registers is not obvious to us - is why grief is less a perception of value than an ongoing attention to facts whose significance is not necessarily readily apparent to us: When in grief, we attend to its object with an inchoate grasp of the significance of that object. We human beings are deeply drawn to narrative as a way of ascribing meaning to sequences of events (witness the countless human origin stories and cosmologies documented by anthropologists, or our susceptibility to fallacious post hoc reasoning), and when a series of emotional states occur in temporal proximity to one another and have a common causal origin, narrating them is a natural and coherent method of organizing them. Hence, grief episodes are clearly amenable to narration. It is therefore unsurprising that bereaved persons often attempt to 'tell a story' about a deceased person and their importance to their lives such that narrative coherence emerges out of grief.

But I am more hesitant to conclude that grief episodes themselves are narratives. For one, grief differs from many narratives in that its components cannot just be fabricated out of whole cloth. When grieving, we cannot just 'make up' whatever elements we wish, in the way that a novelist or playwright has a free hand to introduce characters, plot twists, new settings, and the like. We do not choose the emotional states that strike us during bereavement, nor do we exert much control over their temporal order. So to the degree grief episodes resemble narratives, they are highly constrained in comparison to other narratives we fashion.

Furthermore, narratives have a repertoire of standard components: beginnings and endings, conflicts, climaxes, and resolutions, etc. Locating these components within grief episodes can be difficult, however. Grief responds to the death of another, but it can also be 'anticipatory', i.e., occur in the expectation of a person's future death. And as many clinical accounts attest, grief that seems to have concluded can often recur as events unexpectedly remind 
us of the deceased. ${ }^{13}$ Grief can also have several critical junctures or climaxes instead of just one. And while grief often 'resolves' in the quasi-clinical sense that it diminishes or reaches stasis, its resolution is not obviously a narrative resolution, since that would imply that grief episodes include a central problem to be resolved. Grief thus seems to have a structure but no clear 'plot' to lend it a narrative quality.

At any rate, that grief is a process of emotional attention rather than a unitary perception suggests that the suffering inherent in grief bears normative relations to the other component emotions involved in grief. Our 'resilience,' that is, the diminution of the suffering triggered by this loss, is not the entirety of, or the conclusion of, our ethical engagement with the deaths of our loved ones. The presence or absence of this suffering thus cannot provide the full measure of grief's normative significance for us. We cannot, in other words, extract grief's suffering, examine its duration and intensity, and thereby infer whether we ought to regret being more resilient in the face of others' deaths than we expect. For in doing so, the sufferings of grief are removed from the larger emotional context manifest in the grief process, a context that both provides not only additional information about the nature of the object of grief but information that may prove relevant to understanding that suffering. Whether this resilience merits regret can only be appraised via a fuller grasp of what it is that we attend to through the duration of a grief episode.

2

Grief's Object

The previous section argued that insofar as any perceptual model of grief represents it as a single emotional state governed by straightforward relations of stimulus and response, it gets the response wrong. But there are also grounds for thinking that this model falls short of capturing the stimulus responsible for grief as well.

Brady's attentional model suggests that the various emotional stages that constitute grief are all ways of attending to some states of affairs. But what is the fact that serves as grief's object? More specifically, in what sense are the component affective states of bereavement-anger, sadness, joy, what have you - all about the same fact? To this point, we have spoken generically, and perhaps tritely, of this object as a loss. But what is 'lost' here, and more precisely, given that grief is a process in which we emotionally attend to the significance of another's death instead of a single perceptual event that reveals

13 Worden, Grief Counselling and Grief Therapy, pp. 140-42. 
that significance, what is the 'lost' object that unifies the several stages of this attention?

First, we need not deny that we often feel acute sorrow for what the deceased lose by dying. We may empathize with the plight of those who die prematurely, before various of their projects or goals can be realized. However, the losses suffered by the deceased are not the object of grief. For one, some individuals may benefit from dying, and yet their deaths (rightly) prompt grief. Furthermore, many people presumably suffer such a loss, but our grief does not extend to all of them. Any morally sensitive person is troubled and pained to learn of the thousands or millions of lives snuffed out in genocides or wars. But this sorrow is neither immediate nor fine-grained enough to count as grief.

As a matter of fact, we do not (and I suspect, probably cannot) grieve the deaths of all. Grief is egocentric at heart. We grieve for those with whom we are somehow personally entangled. It is therefore tempting to adopt a straightforward welfarist account of grief's object: that the loss in question is that of the various goods the deceased person provided to the bereaved. Martha Nussbaum rightly emphasizes that we grieve only those on whom we rely as contributors to our flourishing. ${ }^{14}$ But this would imply that grief should diminish, or perhaps should not occur at all, if we could simply replace these goods by (say) identifying another individual to provide them. Yet as Moller notes, ${ }^{15}$ we grieve for those individuals who have become irreplaceable to us. It is this very irreplaceability that makes Seneca's analogy between a deceased friend and a stolen tunic so chilling: "If a man who has lost his one and only tunic through robbery chooses to bewail his plight rather than look about him for some way to escape the cold, or for something to cover his shoulders, would you not think him an utter fool?"16 Moreover, we also grieve those whose contributions to our own well-being ended long ago, or even those whom we hoped would contribute to our well-being but failed us in that regard (children grieve abusive or neglectful parents, spouses grieve those with whom they had unhappy marriages, etc.). Grief thus seems prompted by the deaths of those in whom we have invested our eudaimonic hopes rather than in the deaths of those who in fact have contributed to our well-being. As we shall detail later in this section, grief can feel like an upending of one's normative outlook on the world, precisely because those for whom we grieve are those around whom we have constructed our normative expectations for how we hope our lives will go. So understood, the personal entanglement requisite for grief is ethical, not

14 Upheavals of Thought, pp. 81-82.

15 "Love and death," pp. 309-10.

16 Epistulae Morales 63, Grummere, trans. 
metaphysical. Genuine grief at the deaths of those with whom we share no intimacies (admired political leaders or artists, say) is possible because what they do or have done is perceived as enmeshed with what we desire for ourselves (or for the world at large).

Still, to know whom we grieve for still does not tell us precisely what we grieve for. C.S. Lewis' A Grief Observed is perhaps the most poignant of philosophical memoirs about grief. Lewis' own grief at the death of his wife Joy helps bring the proper object of grief into view. Grief, he writes,

follows marriage as normally as marriage follows courtship or autumn follows summer. It is not a truncation of the process but one of its phases; not the interruption of the dance but the next figure. ${ }^{17}$

Lewis depicts grief not as marking the cessation of an intimate relationship but as a transition within it. His insight seems correct: Because death cuts short many salient facts about those we love, facts that determine the possible ways of relating to them, our relationship with the deceased ought to change accordingly. ${ }^{18}$ Indeed, much of the change necessitated by the deaths of those we grieve for arises from asymmetries between us: Our relationship to a deceased person is no longer a relationship to a peer or equal. We cannot relate to a disembodied, silent person as we relate to a fully corporeal one. We cannot relate to a person with little if any agency in the world as we do to a full-blown practical agent. We cannot relate to a person who, rather than their things going well or badly for them at a given time, is not a subject of welfare at all. We may be able to forgive them but they are unable to forgive us. We can no longer act in concert with, or as a single body with, the deceased so as to manifest what Margaret Gilbert has called "joint commitments." ${ }^{19}$ And so on.

The death of someone in whom we are eudaimonically invested is therefore, to a greater or lesser degree, a catalyst for a crisis in our relationship with them. And as we grieve, our emotional states shift, directed at different aspects of the relationship we had (or hoped to have had) with the deceased.

The intentional object of grief (and I mean here the object of the various emotional states that constitute a grief episode) is a 'loss' of a kind, but is

\footnotetext{
17 (New York: Bantam Books, 1976), p. $5^{8 .}$

18 See S.M. Andersen, and S. Chen, "The relational self: An interpersonal social-cognitive theory,' Psychological Review, 109 (2002), 619-45; Ester Shapiro, Grief as a Family Process: A Developmental Approach to Clinical Practice (New York: Guilford, 1994); and Tony Walter, "A new model of grief: Bereavement and biography," Mortality 1 (1996): 7-25.

19 Joint Commitment: How We Make the Social World (Oxford University Press, 2014).
} 
better described as a forced transition, a shift or modification in how we can and should relate to the deceased. Grief's object - what it is we grieve for as we experience anger, apathy, fear, etc.- -is the loss of the relationship with the deceased as it was (where this also includes hopes or expectations as to how it might have been). What "captures and consumes" our attention as we grieve is this very change.

Thus far, we have argued for two principal conclusions regarding the nature of grief: First, grief episodes are emotional composites, multistate processes rather than singular, sensation-like perceptions. Second, grief's relation to its object is attentional, and more specifically, the particular affective states that constitute a grief episode are directed at different aspects of the grieving person's relationship with the deceased and are collectively directed at the transformation in one's relationship with the deceased that death necessitates.

The conclusions of the previous section point toward a third principal conclusion regarding the nature of grief. As we have noted, grief is less a species of emotional perception than of emotional attention. For practically rational creatures like ourselves, attention will nearly always be organized around some task. When we direct emotionally laden attention to some state of affairs, returning to it periodically over time, our attention tends to acquire a point or purpose. Attention that has no larger aim - attention to some fact for its own sake-is not conceptually incoherent. But our emotionally attending to some fact typically reflects a budding normative investment on our part. When, for example, the fan of an athlete or team watches their performances, her engagement and anticipation seem to have a point or purpose (in this case, to experience both the pleasures and pains of identifying with others' efforts to succeed in their chosen endeavor). Or when the family members of a murder victim attend the trial of the accused, their attendance is a form of emotional attention directed (presumably) at wanting to know the precise fate of their family member and that justice has been done. To emotionally attend to some state of affairs over time is therefore not simply to undergo a set of passive mental episodes. Rather, emotional attention is pregnant with activity. At some point in an arc of sustained emotional attention, our attention transitions from passive to active as we begin to pay attention to the relevant state of affairs. Attending emotionally becomes an exercise of our agency with a point or purpose that we can in principle identify and articulate. 
So too, I suggest, for grief. Grief is a purpose-driven activity wherein our emotional attention to the death of another has a point. But toward what point or purpose do we grieve?

As we saw in the last section, grief's emotional complexity mirrors the complexity of its object. Grief has a stage-like structure with distinguishable affective components because while another's death is the immediate cause of grief, its object - that common fact or state of affairs that unites these affective components and explains how they are components of a single emotional process - is the transformed relationship with the now deceased individual. And as we also observed in the previous section, others' deaths foreclose many of the possible trajectories for our relationships with them. The deceased therefore bequeath to us a predicament, namely how to continue a relationship that cannot proceed on precisely the same terms as before. But for beings whose self-understandings are predicated to a large degree on our relationships with others, the deaths of others in whom we have invested our well-being compel re-examination of the trajectories of those relationships. As authors of our autobiographies, the deaths of these others force authorial choices upon us about how our relationships with them shall continue (given that they cannot continue on their former terms). The process of grief, I propose, is our attempt to resolve this predicament.

As an activity, grief is thus grounded in our efforts to identify how, if at all, our relationship with the deceased will continue in light of the radical change in background realities that their death has wrought. This task is responsible for the emotional grip that grieving can have for us. Our emotional attention is drawn to the deceased individual because we are, however inchoately, attempting to ascertain how we can and will relate to her now and in the future.

Some may doubt that grief is so purposeful as I have suggested. But it is crucial that my claim not be overstated. As a species of emotional attention, grief is not a passive enterprise. As noted above, we cannot dictate how our bereavement will unfold. Nevertheless, we are not powerless in bereavement either. The choices individuals make stemming from grief (for example, choices about how to memorialize the deceased, what is to be done with her belongings, etc.) are, I propose, oriented around the task of determining the trajectory of our relationship with her.

The activity of grief will often be one we pursue without explicit knowledge of our pursuing it. Individuals (such as Augustine) will be drawn to grieve, and hence drawn to emotionally attend to their relationship with the deceased, in order to ascertain how to relate to the deceased going forward but not necessarily by acting under any generic description of this sort. Discrepancies between 
our explicit understandings of our actions and the larger tasks or purposes of which those actions are parts are common. The sports fan does not set aside time to watch her favorite team consciously entertaining the thought that her choice is part of a larger pattern of emotional attention. Activities laden with emotional attention often become habitual or automatic, so it should not be surprising that we frequently engage in them with only tacit knowledge of the point or purpose served by our doing so.

This discrepancy between an activity's purpose and our understanding of our own actions and choices is greatest in the phenomenon we might call quasi-grief. We quasi-grieve when we respond to the death of another with one or more of the phenomenological features of grief-distress and the like-but fail to direct attention at what I have argued is grief's object, the relationship transformed by the death of the deceased. Quasi-grief can arise when grief attends to some other object or when grief fails to attend to any object at all. The latter is likely to occur among those who seek to suppress grief by means of distraction or denial. The former is likely to occur in the early throes of grief when the fact of another's death is a source of emotional disorientation potent enough that grief's object cannot yet come into proper view. In quasi-bereavement, grief reactions are caused by grief's object but do not have that object fully in view. This may seem a strange possibility, but it is not. Intentional states are not necessarily transparent, and the affect associated with an intentional state directed at a given object can mimic the affect associated with a second intentional state directed at another object. In periods of emotional tumult, our self-understanding is likely to be especially susceptible to such misdirection, so that grief is likely to be a phase in which our recognition of its object is halting, gradual, or incomplete. For those in quasi-grief, grief is happening to them, but they are not yet grieving.

Let us make our way back to Moller's question of whether, in light of these claims regarding the nature of grief, the resilience we unexpectedly show in grief merits regret. Unsurprisingly, this question is less straightforward than it appears. For if grief is not a simple perception of another's value or significance to us but an ongoing activity prompted by another's death and oriented toward the relationship necessarily transformed by that death, then the question that should concern us is not whether we should regret the abeyance of grief's suffering. Rather, our question is whether there can be rational grounds 
for regretting how a grief process unfolds as a whole. I shall argue that there can be, precisely because, as he states, we can grieve in ways that "deprive... us of insight into our own condition." Fortunately though, grief is also particularly well-suited both to motivate and enable insight into our own condition.

We have established that the object of grief, that to which the emotional stages of grief attend, is the relationship transformed by the other's death. Grief is thus the manifestation of a 'relationship crisis' instigated by the death of one of the relationship's members. However, because of the nature of the relations we bear to those we grieve, this relationship crisis has an egocentric, identity-based face. Many bereaved people report a sense of disorientation, of not feeling at home in the world or in their own skins. Oftentimes, grieving persons undergo alienation or a loss of self-recognition, ${ }^{20}$ sometimes described in physical terms akin to amputation. ${ }^{21}$ "I feel like I've lost a part of myself," many bereaved persons say. This claim is true in one sense: As social animals, our own natures are individuated to a large degree by our relationships with others. And except in the rarest cases of alienation, our concerns and commitments depend on the existence of others in whom our eudaimonic hopes have been invested. "When someone dies," Colin Parkes observes, "a whole set of assumptions about the world that relied upon the other person for their validity are suddenly invalidated."22

Grief thus raises questions of self-identity and self-definition in especially acute ways. The relationship crisis found in grief is therefore simultaneously a crisis in practical identity, that description under which we value ourselves and take ourselves to have reasons to act as we do. ${ }^{23}$ We suffer in grief in part because another's death poses a threat to our practical identities. In the case of grief, the threat is not literal or physical but ethical or normative. ${ }^{24}$ The death of someone in whom our eudaimonic hopes are invested jostles our practical identity. Our sense of our own projects and commitments is shaken, not in the sense that we necessarily come to doubt those projects and commitments

$20 \quad$ James Morey (1995) Living with Grief and Mourning (Manchester: Manchester University Press, 1995) and Colin Parkes and Holly Prigerson, Bereavement: Studies of Grief in Adult Life. 4th ed. (New York: Routledge, 2010).

21 Lewis, A Grief Observed, p. 86. See Matthew Ratcliffe, "Grief and phantom limbs: A phenomenological comparison,” unpublished ms. [https://www.academia.edu/31530074/ Grief_and_Phantom_Limbs_a_Phenomenological_Comparison], accessed Aug 26, 2017.

22 Bereavement: Studies of Grief in Adult Life (London: Penguin, 1996), p. 90.

23 Christine Korsgaard, The Sources of Normativity (Cambridge: Cambridge University Press, 1996), p. 101.

24 Though it should not be surprising that grief can often have physical 'symptoms' as well, including digestive difficulty, fatigue, muscle aches, etc. 
(though that can be an upshot of grief). The other's death is instead akin to hearing the creak of floorboards in an aging building. The creak is not necessarily a sign the building should be torn down. But it reminds us that in depending upon that structure, we depend upon something vulnerable to age, time, and deterioration. To the extent our practical identities are metaphysically and normatively entangled with others, those others' deaths bring the vulnerability, and ultimate contingency, of our practical identities into stark relief. $^{25}$

When we engage fully with grief, we engage with the contingency of the material facts on which our ongoing normative commitments depend. By being compelled to bring one's relationship with the deceased into the emotional spotlight, grief likewise compels us to bring our practical identities into the emotional spotlight as well - to subject them to normative articulation, scrutiny, ratification, or revision. Grief thus represents a unique opportunity for what Quassim Cassam has called "substantial self-knowledge," knowledge of our "values, emotions, abilities, and of what makes one happy." ${ }^{26}$ In undergoing joy, anxiety, anger, etc., as stages in a grief process, we are afforded an opportunity to catalog or take stock of the fundamental cares or concerns around which we organize our lives. For example, suppose a child experiences the death of a parent whom the child consciously emulated, even choosing to enter the parent's chosen profession (medicine, say). The parent's death will likely underscore to the child both the parent's role in leading her to choose a medical career and the contingency of that choice. And it is when we recall that our practical identities are to some degree chosen rather than fated that we tend to interrogate them. In this case, that interrogation could have several different results. The child may end up questioning her choice on the grounds that opting for medicine was an attempt to win the approval of a parent whose approval she can no longer seek. Or the child may come to see that medicine was a wise choice despite its being so motivated - a fortuitous decision made on regrettable grounds. Alternatively, the parent's death may illustrate to the child the nobility of medicine as a profession. (One can imagine how the medical

25 Harry Frankfurt, The Importance of What We Care About (New York: Cambridge University Press, 1988), p. 83. Indeed, it is a mark of feigned grief that the bereaved is not eudaimonically invested in the deceased's continued existence. See Tony Milligan, "False emotions," Philosophy 83 (2008): 213-230, and Troy Jollimore, "Meaningless happiness and meaningful suffering," Southern Journal of Philosophy 42 (2004), pp. 339-40.

26 Self-knowledge for Humans (Oxford: Oxford University Press, 2014), p. 10. Thomas Attig defends a similar claim, arguing that grief involves "relearning" our selves, the world, and our relationship with the deceased (How We Grieve: Relearning the World, revised edition (Oxford: Oxford University Press, 2011). 
circumstances of the parent's death-whether it was prolonged or brief, whether the parent received adequate care, etc.-could play an especially prominent role here.)

My account of how grief catalyzes self-knowledge is neutral between 'rationalistic' conceptions of self-knowledge, in which knowledge is the product of rational endorsement of some attitude rather than the perception or discovery of some attitude, ${ }^{27}$ and other conceptions. We may see the self-knowledge in question as the result of efforts at justifying our practical identities, at discovering our practical identities, or some combination of both. In the case described above, of the child who followed her deceased parent into medicine, the conclusions regarding her chosen profession that her grief process leads her to affirm may rest on discoveries of emotions, values, concerns, etc. that temporally anteceded the pursuit of self-knowledge embedded in that process. But it is no less possible that the conclusions she affirms are genuinely novel, at odds with whatever emotions, values, concerns, etc., existed prior to the grief process. In many instances, the process of diagnosing our emotions, values, concerns, etc., will occur side by side with the critical appraisal of them. For emotions have a dual epistemic role, motivating us to search both for evidence to corroborate how the emotions represent our concerns and for evidence that these concerns are concerns we ought to have. ${ }^{28}$

As Cassam observes, substantial self-knowledge-knowledge of our central evaluative attitudes, emotions, values, etc., as opposed to 'trivial' selfknowledge such as knowing that one believes that one is wearing socks - is difficult to attain. Grief is likely to be a particularly fruitful source of substantial self-knowledge though. Given (a) that we grieve for those in whom we have invested our eudaimonic hopes, (b) how acutely their deaths underscore the contingency of our practical identities, and (c) the range of emotional responses found in grief episodes, grief makes available an astonishingly wide range of evidence regarding who we are and what we care about. When in the course of grief, I become angry, I am afforded evidence regarding what I value and what I perceive as a threat to that value. When in the course of grief, I become depressed, I am (again) afforded evidence regarding what I value and what sorts of losses of what I value are most acute. And so on. Grief is thus a lens on the complex tapestry woven from the various threads that constitute our practical identities. We should be thus grateful for the opportunity to grieve, for grief is

\footnotetext{
27 See among others Gareth Evans, Varieties of Reference, J. McDowell ed. (Oxford: Oxford University Press, 1982), p. 225, and Richard Moran, Authority and Estrangement (Princeton: Princeton University Press, 2001). 
not just any occasion for self-knowledge. It represents a rare opportunity to see our practical identities both in detail and as a whole.

My claims regarding grief and self-knowledge should not be exaggerated. I claim that grief's causal power to upend the material assumptions around which our practical identities are built make it both a powerful motivator of and opportunity for substantial self-knowledge. I do not claim that selfknowledge is essential to grief - that absent self-knowledge or the pursuit thereof, a person is not grieving. Nor do I claim that grief alone is a source or occasion for such self-knowledge. Indeed, other similarly disruptive events within personal relationships (divorce or estrangement, say) can perform the same normative function. That grief is a particularly potent motivator and opportunity for self-knowledge does not mean it has a monopoly on the means to self-knowledge. But I take this fact not to be a mark against my account of grief's nature or significance. Rather, this observation helps us see grief as perhaps the paradigm case to illustrate how our interdependence and entanglement with others make our practical identities dependent upon, and therefore emotionally vulnerable to, the fates of others. Nor do I claim that all the selfknowledge we might attain can be attained only via grief. Indeed, grief will often enable us to build upon, draw out, or disentangle self-knowledge we already possess. For in almost every case, the bereaved embark on grief already having some measure of self-knowledge with respect to the deceased, knowing (at least in generic terms) that the deceased mattered as one's parent, sibling, co-worker, etc.

Seeing self-knowledge as the distinctive good afforded by grief also indicates the path marked out by healthy grief episodes. As Daniel Russell points out, it is far from obvious that the aim of our 'working through' our grief should be to detach ourselves from the deceased loved one, as Freud maintained. On the contrary, grief seems healthiest when the bereaved is able to continue her attachment to the deceased under the new terms necessitated by death. ${ }^{29}$ Again, this does not entail the cessation of the bereaved's relationship with the deceased. Our relationships to the dead continue, both emotionally and symbolically. Rather, bereavement should be guided by the goal of establishing a new, more stable trajectory for one's relationship with the deceased, incorporating the relationship's history prior to death. In pursuing this goal, the bereaved person also seeks a stable conceptualization of herself and her concerns in light of the relationship transformed by death. The end result of grief is thus,

29 Happiness for Humans, pp. 224-27. I therefore have reservations about Smuts' claim ("Love and death: The problem of resilience") that resilience ought to be regretted because it represents the "death of self," if taken literally. 
as Tony Walter has put it, to fashion a "durable biography" that integrates the memory of the deceased individual into their practical identities. ${ }^{30}$ Substantial self-knowledge, I have proposed, is the good that results from this process.

\section{$5 \quad$ Too Egoistic, Too Grandiose?}

I have argued that grief's suffering can only be understood or appraised in the context of the totality of emotional responses that constitute the grief process, and all the more, in the context of the forward-looking enterprise of defining one's relationship to a deceased individual to whom one retains some form of attachment. All the same, Moller was correct in concluding that grief can go awry when it "deprives us of insight into our own condition." For as I have argued, grief is a distinctive opportunity for, and motivator of, substantial selfknowledge of our practical identities.

Before returning to Moller's question of whether resilience in the face of grief merits regret, let me address some possible worries regarding the claims I have made about the nature of grief and its normative significance for us.

One worry is that my account of grief's value renders grief too self-centered. For as I have depicted grief, it may seem like grief does not engage with the deceased in a rich way. Grief, on my account, seems solipsistic and self-absorbed, even if its eudaimonic aim of self-knowledge is a noble one.

In one respect, this objection is correct. For in attempting to understand grief, I take myself to be attempting to grasp the specifically egocentric reactions the deaths of others can prompt in us. As argued in section 2, grief is a selective response. We grieve only the deaths of those who mattered to us in specific ways. Yet it is entirely compatible with others' deaths eliciting other, non-egocentric responses in us. Mourning, for instance, seems to take as its object the deceased individual herself and the loss that her death represents to her. Because many others can grasp how death might represent such a loss to the deceased, many can mourn a person's death, but only some can grieve in response to it (and some can and will do both). A nation can mourn its war dead, but only those with the specific eudaimonic investment in the individual service members can genuinely grieve their deaths.

Still, one might press this objection further, claiming that my account of grief removes the deceased from the heart of the grief experience. This is not so, however. For though I have argued that grief is directed at one's relationship with the deceased, one cannot interrogate this relationship without in

$30 \quad$ "A new model of grief: Bereavement and biography." 
some way interrogating the deceased, and discoveries and insights about the deceased that arise in the course of grief do not register with the bereaved merely as normatively inert curiosities about the deceased. Those facts are taken as facts about the deceased and the bereaved, facts to be integrated into the bereaved individual's understanding of their relationship, and by extension, into her self-understanding. This process of enhancing self-knowledge, while it culminates in a good to oneself, is not narcissistically focused on oneself. Within the grief process, bereaved individuals may not be able to cleanly distill the process of knowing the deceased from knowing themselves. As Samuel Scheffler has suggested, inasmuch as grief is a process through which individuals "register the extent of their dependence on, vulnerability to, and entanglement with other people and their fates" the "attitudinal reactions" that constitute grieving often cannot be readily categorized as egoistic or altruistic. ${ }^{31}$

One might instead find my account of grief's nature and significance too grandiose. What is wrong with characterizing grief more plainly, in terms of being sad at another's death? I do not deny that sadness or suffering are essential ingredients of grief. But to reduce grief to this sadness overlooks its complex emotional texture and inhibits differentiating grief from other reactions we have to others' death (mourning among them). It would be an exaggeration to deny the possibility of a grief episode that involved only sadness, i.e., a grief 'process' with only an emotional perception or state. Nevertheless, grief episodes of this sort appear to be rare. And even here, such sadness can be informative regarding the significance of the bereaved's relationship with the deceased and thus a catalyst for self-knowledge.

6

Resilience and Regret

Let us now address whether the resilience to which Moller refers should be regretted. On my account, this depends upon what such resilience shows about whether a grief episode generates self-knowledge. And as one might anticipate, my own answer is complex, for there is no regular connection between the presence or absence of suffering associated with grief and the achievement of self-knowledge.

One way in which another's death may not lead to self-knowledge is simply not to grieve at all. Such appears to be the reaction of Meursault, the principal

31 Death and the Afterlife, p. 180. Donald Baxter, "Altruism, grief, and identity," Philosophy and Phenomenological Research 70 (2005): 371-83 proposes that grief calls into question the very distinctness of selves presupposed by the contrast between egoism and altruism. 
character in Camus' The Stranger. ${ }^{32}$ Of course, in such cases, questions understandably arise as to whether such individuals are even capable of relating to others in such a way that grief at their deaths is an intelligible response.

Yet even those whose grief is genuine (i.e., directed at its proper object) may nevertheless fall short of self-knowledge. As we have seen, grief is not an affectively laden perception of a singularly valenced evaluative fact. Rather, it is an ongoing emotional activity, characterized by multiple emotional states, in which the bereaved attempt to establish new terms for their relationship with the deceased, and in so doing, acquire self-knowledge of their own values, cares, and concerns. In the case of less complex emotions, the goods these emotions make available can often be readily accessed or achieved. To feel fear upon hearing a loud thunderclap usually leads people to be startled and to locate, and thereby avoid, the danger that fear registers. The relationship between an emotional activity like grief and the good it affords us is looser, however. For one, individuals will vary in their aptitudes at a given activity. We are not equally well-equipped with respect to the emotional discernment likely to be helpful in establishing new terms in our relationship with the deceased. Achieving self-knowledge via the process of grief may be aided by moral or epistemic virtues (for example, curiosity, intellectual steadfastness, or courage) that are not equally distributed. Grief episodes will also vary in how tractable and amenable to self-knowledge they are. For those who stood in strong relationships with the deceased-those whose relationships were transparent and mature - grief may require little in the way of articulating the significance of that relationship for one's practical identity. The grief in question may amount to little more than missing the deceased individual. Self-knowledge can come easily here, with modest and relatively manageable emotional distress. For a good many others, grief may become problematic or "complicated." Those whose relationship with the deceased was more troubled, or those with narcissistic personalities for whom the deaths of others challenges their selfconception as independent or invulnerable, ${ }^{33}$ are likely to find the articulation and eventual appreciation of the relationship in question more elusive or daunting. Finally, the generic difficulties of attaining knowledge (our susceptibility to wishful thinking, bad inferences, etc.) are likely to plague any activity suited to the attainment of self-knowledge.

\footnotetext{
32 For a discussion of The Stranger as a commentary on the incapacity to grieve, see Michael Cholbi, "Finding the good in grief: What Augustine knew but Meursault could not," Journal of the American Philosophical Association 3 (2017): 91-105. 
There are grounds for skepticism about the arduous and emotionally taxing "grief work" often described in contemporary clinical writings on grief. Nevertheless, my account of the nature and value of grief acknowledges that grieving is effortful while acknowledging that it is not paradigmatically painstaking or traumatic. So depicted, grief is thus a therapeutic cum epistemic undertaking. It is therapeutic not because grief is necessarily traumatic or diseased, nor because it often results in healing of psychological wounds. Rather, it is 'therapeutic' in the Greek sense of being a way of attending to someone, of directing concerted attention to the relationship death necessarily transforms, and by extension, to one's one eudaimonic commitments. It is epistemic because the good it generates is a species of self-knowledge. This epistemic facet of grief helps explain the oft-noted withdrawal of the bereaved. For many, grief induces a period of introspection, and on my view, such introspection represents part of the effort by which the bereaved seek to articulate the significance of the relationship recently transformed by death, and by extension, to achieve a greater measure of self-understanding.

We are not omnipotent with respect to our own grief, but neither are we pure spectators. Whether we should regret being resilient in the face of grief concerns as much what we do as we grieve as what happens to us during grief. The particular affective states that make up a grief episode strike us unbidden. Yet we can influence our second-order attitudes toward the justifiability of these states, and consider the justifiability of these states as representations of our relationships with the deceased, both as they were and we might want them to be. In so doing, we position ourselves to attain valuable self-knowledge. Resilience in the wake of grief is thus regrettable when we squander the opportunity to attain self-knowledge. As Williams put it, the "constitutive thought of regret in general" is akin to "how much better if it [some state of affairs] had been otherwise." 34 But the regret at issue in grief is not what Williams terms spectator-regret, regret directed at the fact that some state of affairs has occurred. Rather, the regret at issue is primarily agent-regret, regret directed at an outcome which one had a hand (even if only by omission) in bringing about.

Emotions make our cares and concerns salient, and so serve to disclose and open to scrutiny our practical identities. We should welcome the opportunity to grieve because the emotional complexity of grief makes it an especially 
fertile source of self-knowledge and self-understanding. And we should only regret the resilience often shown in the face of grief if and because such resilience marks the cessation of grieving that failed to yield self-knowledge.

That said, those who do not grieve, who quasi-grieve, or who grieve without attaining further self-knowledge do not undergo a state that is intrinsically bad, affectively or otherwise. Their loss is a comparative one. Their lives are less good than they could have been. Of course, this assumes that selfknowledge is good, a claim about which philosophers have said surprisingly little and which must wait for another occasion. ${ }^{35}$ 


\section{Author Query:}

AQ1: Please check the sentences affect or effect? 